\title{
Analysis of Aeroheating Augmentation due to Reaction Control System Jets on Orion Crew Exploration Vehicle
}

\author{
Artem A. Dyakonov*, Gregory M. Buck ${ }^{\dagger}$ \\ NASA Langley, Hampton, Virginia, 23681, USA \\ and Anthony D. Decaro $\ddagger$ \\ ELORET, Sunnyvale, California, 94086, USA
}

\begin{abstract}
The analysis of effects of the reaction control system jet plumes on aftbody heating of Orion entry capsule is presented. The analysis covered hypersonic continuum part of the entry trajectory. Aerothermal environments at flight conditions were evaluated using Langley Aerothermal Upwind Relaxation Algorithm (LAURA) code and Data Parallel Line Relaxation (DPLR) algorithm code. Results show a marked augmentation of aftbody heating due to roll, yaw and aft pitch thrusters. No significant augmentation is expected due to forward pitch thrusters. Of the conditions surveyed the maximum heat rate on the aftshell is expected when firing a pair of roll thrusters at a maximum deceleration condition.
\end{abstract}

\section{Nomenclature}

$\alpha \quad$ Angle of attack, degrees

$\beta \quad$ Angle of sideslip, degrees

$\beta \quad m / C_{D} A$, ballistic coefficient

$D \quad$ Capsule diameter, $\mathrm{m}$

$h / h_{\text {re }}$ Non-dimensional heatflux

$q \quad$ Heat flux, $W / \mathrm{cm}^{2}$

Re Reynolds number

$T$ Temperature, $\mathrm{K}$

$V \quad$ Velocity, $\mathrm{m} / \mathrm{sec}$

Subscript

$\infty \quad$ free-stream

conv convective

$D$ based on diameter

\footnotetext{
*Aerospace Engineer, Atmospheric Flight Entry Systems Branch, AIAA Member.

$\dagger$ Aerospace Engineer, Aerothermodynamics Branch, AIAA Member.

¥Aerospace Engineer, Reacting Flow Environments Branch, AIAA Member.
} 


\section{Introduction}

The Orion Earth entry capsule is being designed to be a part of the Constellation architecture, the next generation of NASA's human space exploration systems. The Orion capsule will carry crew to and from space, and its mission calls for a lifting actively guided profile of its entry to Earth. During atmospheric entry Orion will use aerodynamic lift for guidance maneuvers and a reaction control system (RCS) will be used to alter direction of the lift vector and capsule's attitude rates in all flight regimes as required. Because the RCS will produce under-expanded jets of thruster exhaust, the effect of the interaction of these jets with the capsule's gas-dynamic environment must be understood. Namely, effects of jets on the capsule's aeroheating is of interest insofar as it can impact sizing and design of the Thermal Protection System (TPS), and the effect of jets on the pressure field around the capsule needs to be assessed to determine if any significant interference with RCS control authority might be expected. While there is a significant overlap in the means to achieve the two objectives, the present report will focus only on the aerothermal environment.

\section{A. Description of Orion Reaction Control System}

Because Orion is designed to fly a lifting actively guided trajectory, the capsule is equipped with a Reaction Control System (RCS) composed of 12 hydrazine (N2H4) thrusters, placed on the aftshell in an arrangement somewhat similar to that of Apollo system. Thrusters are configured to produce pitch and yaw torques to help dampen attitude oscillations and to control the bank angle. In the off-nominal situations roll thrusters may be used to take out persistent aerodynamic torques that might originate from uneven heatshield ablation or other aerodynamic issues that can not be mitigated otherwise due to lack of aerodynamic stiffness in roll axis. ${ }^{1}$ As configured, the thrusters will be used at various times during entry as needed and as commanded by guidance. Thruster layout is shown in the figure 1 . Current analysis uses a chamber pressure $p=200$ psia, a chamber temperature $T=2000^{\circ} \mathrm{F}$ and an effective supersonic area ratio $A R=25$. Notably most of the nozzles on the vehicle are scarfed because of the angle between the thruster axis and the vehicle's outer mold line (OML) introducing added complexity in the jet flow. Thrusters are arranged in pairs as shown.

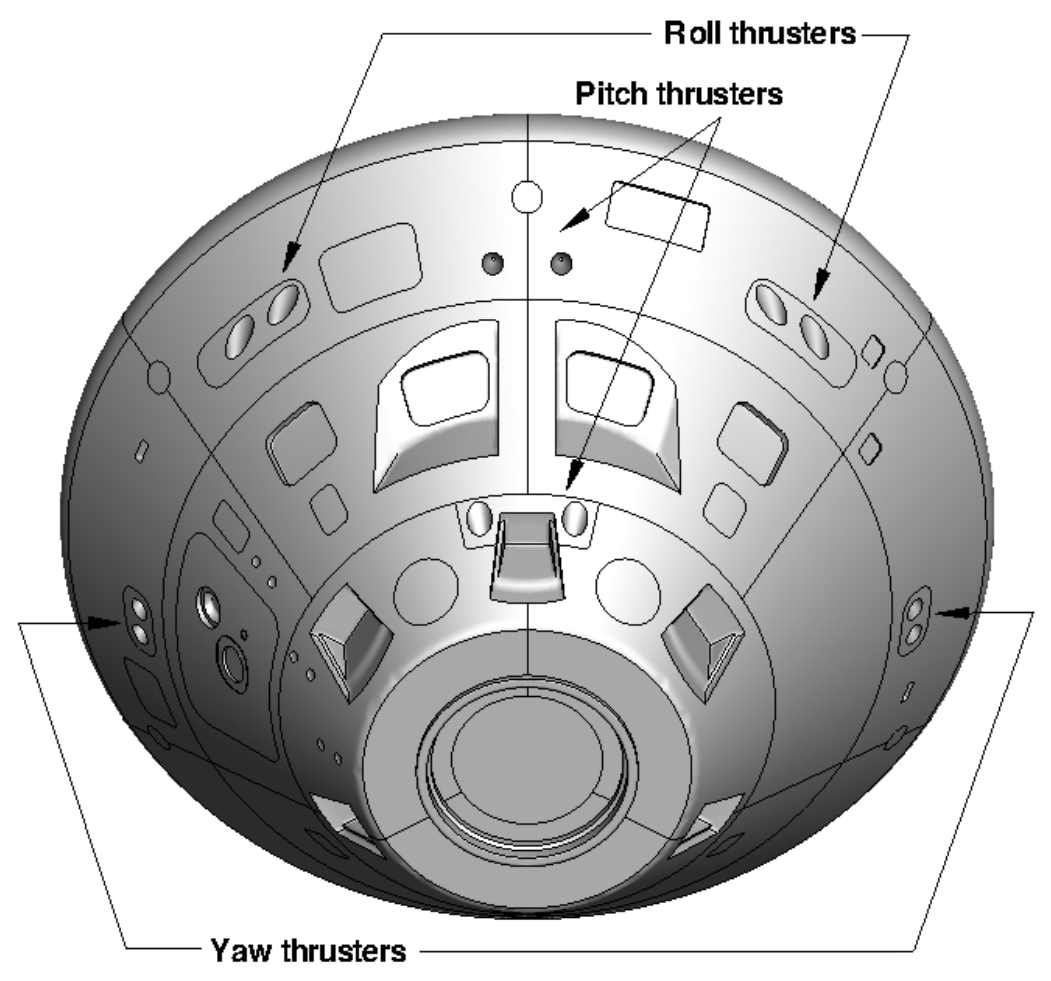

Figure 1. Layout of Orion RCS. 


\section{B. Flight Conditions}

Several hypersonic conditions have been identified for this analysis and are shown in the table. Conditions shown represent a skip entry which is currently a baseline.

\begin{tabular}{|c|c|c|c|c|c|}
\hline \multicolumn{7}{|c|}{ Free stream conditions } \\
\hline \hline Mach & $\mathrm{V}_{\infty}, \mathrm{m} / \mathrm{sec}$ & $\rho_{\infty}, \mathrm{kg} / \mathrm{m}^{3}$ & $\mathrm{~T}_{\infty}, K$ & $\operatorname{Re}_{D}$ & $\alpha$, degrees \\
\hline 33.9 & $10.50 \mathrm{E} 3$ & $2.173 \mathrm{E}-4$ & 239.0 & $2.724 \mathrm{E} 5$ & 18 \\
\hline 31.2 & $9.830 \mathrm{E} 3$ & $3.173 \mathrm{E}-4$ & 247.3 & $3.767 \mathrm{E} 5$ & 18 \\
\hline 25.9 & $8.000 \mathrm{E} 3$ & $1.974 \mathrm{E}-4$ & 237.0 & $1.880 \mathrm{E} 5$ & 18 \\
\hline 21.1 & $6.600 \mathrm{E} 3$ & $2.837 \mathrm{E}-4$ & 244.8 & $2.254 \mathrm{E} 5$ & 18 \\
\hline 18.4 & $6.000 \mathrm{E} 3$ & $6.782 \mathrm{E}-4$ & 264.6 & $5.001 \mathrm{E} 5$ & 18 \\
\hline 15.2 & $5.000 \mathrm{E} 3$ & $1.465 \mathrm{E}-3$ & 270.4 & $9.042 \mathrm{E} 5$ & 18 \\
\hline 12.4 & $4.000 \mathrm{E} 3$ & $2.426 \mathrm{E}-3$ & 260.2 & $1.188 \mathrm{E} 6$ & 18 \\
\hline 6.43 & $2.000 \mathrm{E} 3$ & $6.852 \mathrm{E}-3$ & 240.6 & $1.640 \mathrm{E} 6$ & 18 \\
\hline
\end{tabular}

\section{Flow Characterization}

In hypersonic regime the flow around Orion capsule is characterized by the presence of a bow shock, supersonic expansion fan, located at the shoulder, followed by separation of the supersonic flow, forming a region of low energy recirculating air, and a recompression shock (figure 2). Because the present analysis is focused on the events mainly in the recirculating zone, a good understanding of the upstream and surrounding events is required. It is also important to be mindful of the fidelity in the numerical analysis tools with respect to each of the unit-sub-processes that make up the flowfield.

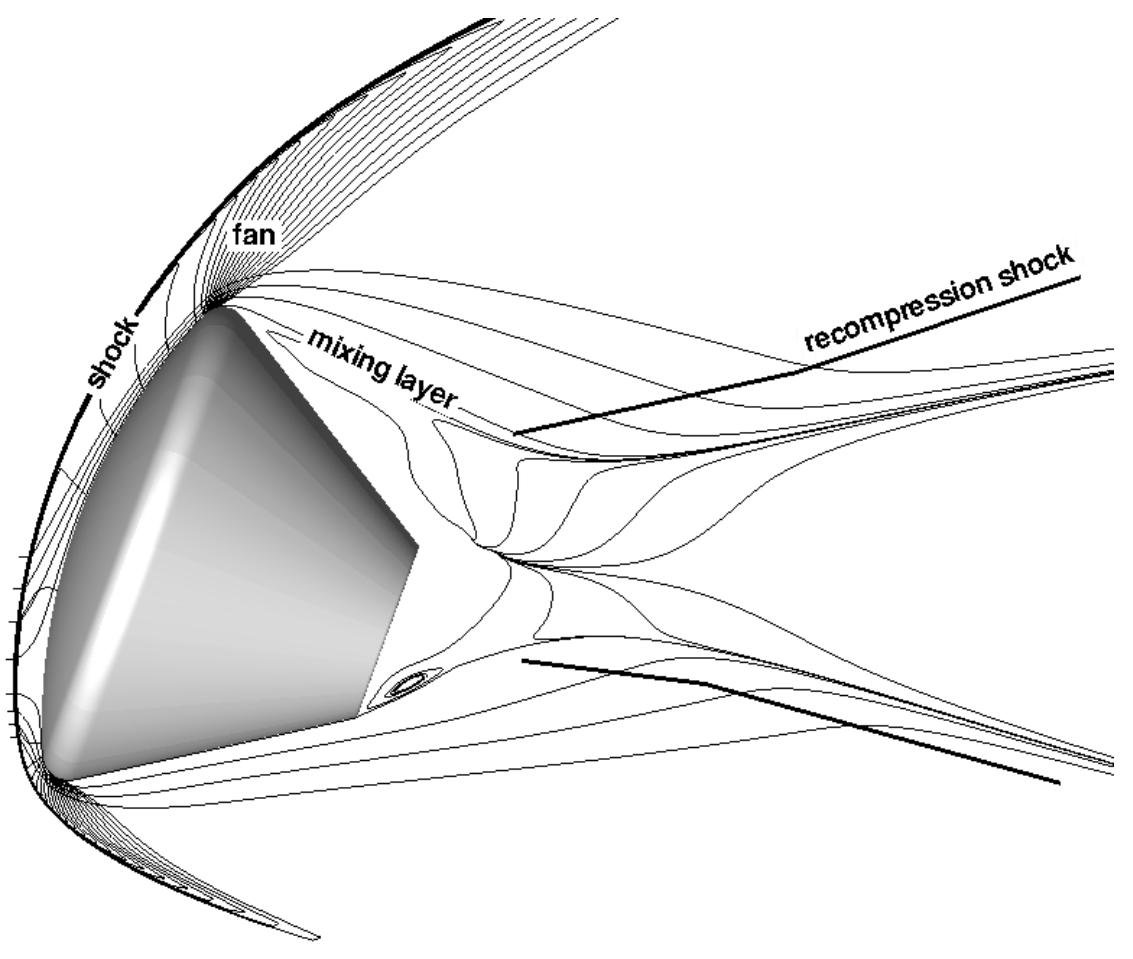

Figure 2. Schematic of hypersonic flowfield. 


\section{A. Shocklayer}

Shocklayer on the forebody of the capsule is composed of a chemically reacting and sometimes non-equilibrium gas mixture. Most of the shocklayer is subsonic, with parts of lee-side forebody flow becoming low-supersonic. Current Agency's numerical tools (LAURA ${ }^{2}$ and DPLR $^{3}$ ) have been shown to accurately capture the bow shock shape and distance from a blunt body at hypervelocity (see, for example Horvath ${ }^{4}$ ), pressure and heating on the surface for both laminar and turbulent boundary layers. ${ }^{5}$ It is, therefore, reasonable to rely on LAURA and DPLR to solve the leading segment of the flowfield and to expect accurate results.

\section{B. Expansion fan}

The expansion fan at the capsule shoulder accompanies flow turning to align with the windside aftshell on the windside and with the lee-side mixing layer on the leeside. Generally the expanded flow reaches Mach number around 4 for much of hypersonic flight. Fidelity of computations through the expansion is difficult to quantify. The more practical parameter to consider is the heat flux, predicted on the windside aftbody surface. Comparisons between computation and wind tunnel measurements, carried out for that area by Hollis ${ }^{5}$ show that the heat flux predictions in both laminar and turbulent flowfields are simulated accurately on the Orion shape with the use of numerical tools. This indicates that the parameters of the flow immediately after the expansion are correct.

\section{Mixing layer and the recirculating zone}

The mixing layer divides the supersonic high energy flow from the recirculating zone of low energy air near capsule's leeside aftbody. The mixing layer determines the balance of mass, momentum and energy transport between these two highly dissimilar regions. Accurate prediction of the transport across the mixing layer and its geometry is vital to pressure and enthalpy of the air inside the recirculation zone, as well as to the accurate solution of expansion in the lee-side external flow, as it is influenced by the wake angle. Nominal operation of tools, such as LAURA and DPLR results in inadequate grid density in the wake and incorrect grid alignment with respect to the mixing layer. Significant additional grid density is required, together with some suitable grid alignment procedure, to provide the solution domain for the mixing layer (see, for example, Hollis ${ }^{6}$.

Discussion of the simulation of transport phenomena across the mixing layer must include a discussion of turbulence. The mechanism, postulated by Chapman ${ }^{7}$ required that the mass of recirculating air that is evacuated by the mixing layer is replaced through the layer itself near the trailing end of the recirculating zone. If all or part of the layer is turbulent - this balance will be affected, resulting in a different shape of the mixing layer and a new pressure of the recirculating air. Because of the extent to which turbulent transition in the nixing layer can affect the outcome of the wake analysis, it should be determined if turbulence in the layer is likely. Focus is made here on the likelihood of turbulence in the free shear layer, which separates air in the high-energy external flow and the lower-energy recirculating air, and in the recirculating region itself.

Figure 3 shows the predicted variation of the local Reynolds number in the flowfield at a free-stream $\mathrm{M}=6.5(2 \mathrm{~km} / \mathrm{sec})$ flight condition. At this flight condition free-stream Reynolds number is increasing in the direction of reducing velocity, so as far as hypersonic conditions are concerned, the conditions of higher heating will produce lower Reynolds number in the flowfield. The purpose of the figure is to illustrate a region of a relatively constant local Reynolds number just above the leeside free-shear layer. Magnitudes around $\mathrm{Re}=1.0 \mathrm{E} 5$ are prevalent in the region.

It has been shown (for example, see von Doenhoff ${ }^{8}$ ) that low speed free shear layers are more susceptible to turbulent transition then attached boundary layers. In other words, for the same Reynolds number, free shear layers transition earlier then attached boundary layers. However, at high Mach numbers, mixing layers have been shown to exhibit remarkable stability. ${ }^{7}$ For example, the laminar limit of about Re=1.E6 was shown for Mach 4 flows for a wide range of flowfield geometries. This is particularly significant in the context of the present discussion involving a hypersonic free shear layer. Given the running length of the free shear layer of roughly one capsule's diameter ( 5 meters) there appears to be a good reason to expect a laminar shear layer, which might transition only toward the end of the recirculating region.

The mixing layer establishes the interface between the external flow and the recirculating zone. The recirculating zone contains a mass of air, whose total enthalpy is between 15-50 percent of that in freestream. The air mass, its enthalpy and momentum is provided from the exterior flow through diffusion across the mixing layer, and is, therefore, directly affected by whether the layer is laminar or turbulent. The 


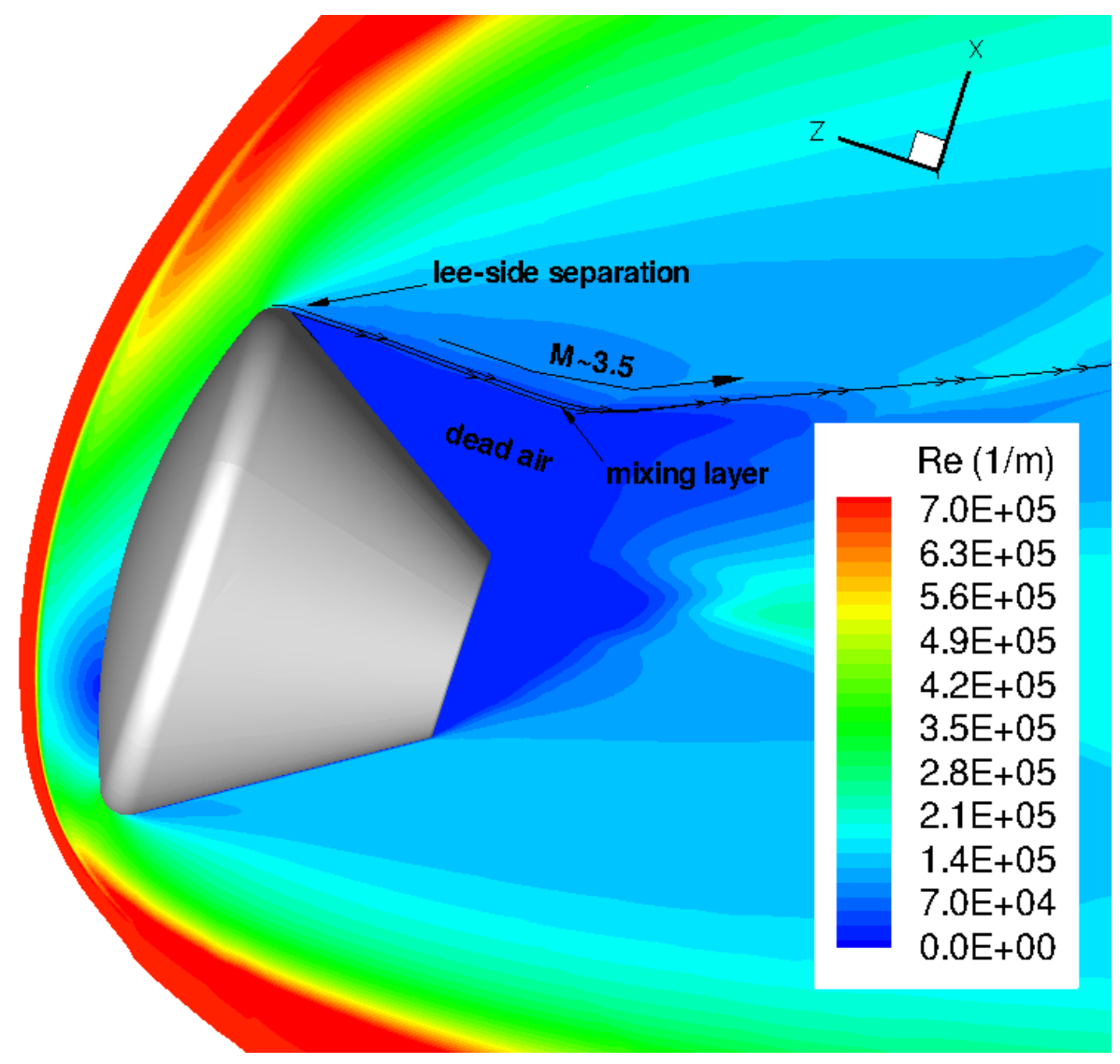

Figure 3. Variation of the Reynolds number in the flowfield.

state of the mixing layer is, therefore, a critical player in the pressure and enthalpy of the recirculating air. Above assessment of 15-50 percent is based on numerous CFD calculations using a laminar model over a broad range of Mach.

The state of the flow inside the recirculating region is not necessarily coupled to the state of the mixing layer. Inside the recirculating zone the predicted local Reynolds number at the Mach 6.5 flight condition stays below about 1.E4 and the flow scale length there is of the order of a meter. It appears unlikely that such a flow will develop and sustain turbulence, instead it should remain laminar, even if unsteady and vortical. Unfortunately, present leeside aftbody heating data ${ }^{5}$ doesn't allow to determine if heating in the dead air zone is laminar or turbulent.

Presently work is ongoing to determine how to best model the wake environment, however, the baseline environment is computed turbulent, and RCS augmentation factors are derived from CFD solutions that are laminar.

\section{Intersecting Supersonic Streams}

Introduction of under-expanded RCS effluent into the wake of the capsule of the Orion vehicle produces several types of interactions. When yaw jets are active, a supersonic jet interacts with essentially an attached supersonic crossflow along side of capsule, resulting in changes to the local flow as is typically expected from this type of an interaction. ${ }^{9}$ Variance of the actual flowfield from the generic under-expanded jet in a supersonic crossflow system results from the jet exit angle, jet-jet interaction (for jet pair) and surface curvature and flow parameters and gradients.

When roll jets are active, they penetrate the recirculating zone and intersect the supersonic shear layer, resulting in an energetic interaction with the supersonic exterior flow, displacing it. Resultant recovery of pressure forces some of the high enthalpy flow into the near-wall space in front of the jet, causing increased heating and pressure at the wall. This is phenomenologically very similar to the more general jet-in-the- 
crossflow system. When rear pitch jets are active, they mostly reshape the recirculating zone and have a comparatively little effect on the external supersonic flow. As configured, forward pitch jets have little opportunity to reshape the exterior flow, while the aft yaw jets could Generally, there is a lot of similarity between the first two types of interaction. Differences arise from such discriminators as the flow angles, Mach and pressure profile in the approaching flow, curvature of the surface underneath the interaction and the presence of the separation in the baseline flow. Figures 4, 5,6 and 7 show these different types of interaction computed by LAURA for Orion at a hypersonic condition. Red transparent surface illustrates a boundary of RCS effluent and allows to visualize diffusion of effluent as the plume reaches into the external flow. Heat flux (without uncertainties) is also shown in all of the figures to illustrate the computed extent of the aeroheating augmentation due to the thruster plumes.

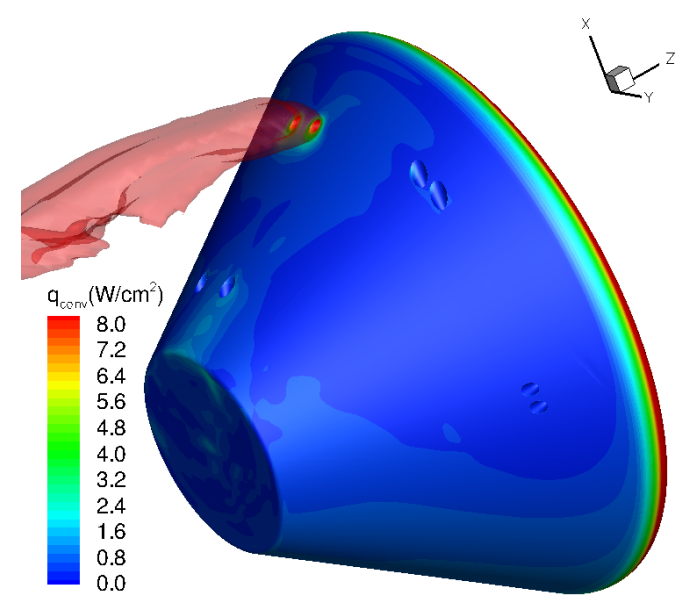

Figure 4. Flowfield, forward pitch jets, $4 \mathrm{~km} / \mathrm{sec}$

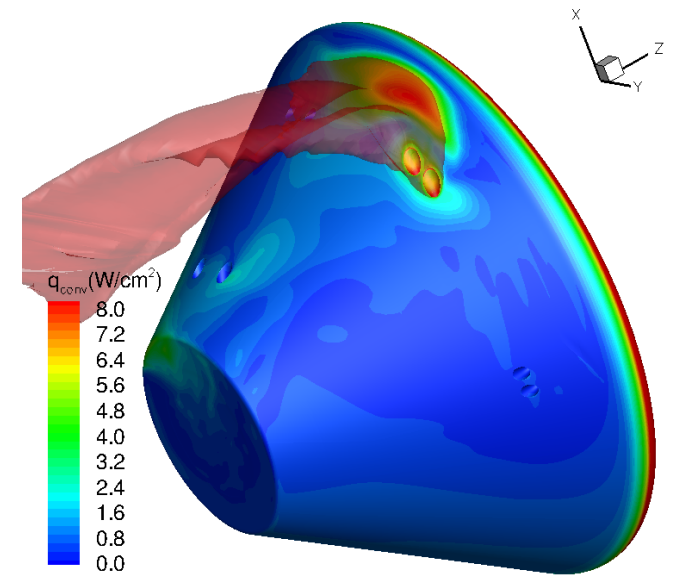

Figure 6. Flowfield, forward roll jets, $4 \mathrm{~km} / \mathrm{sec}$

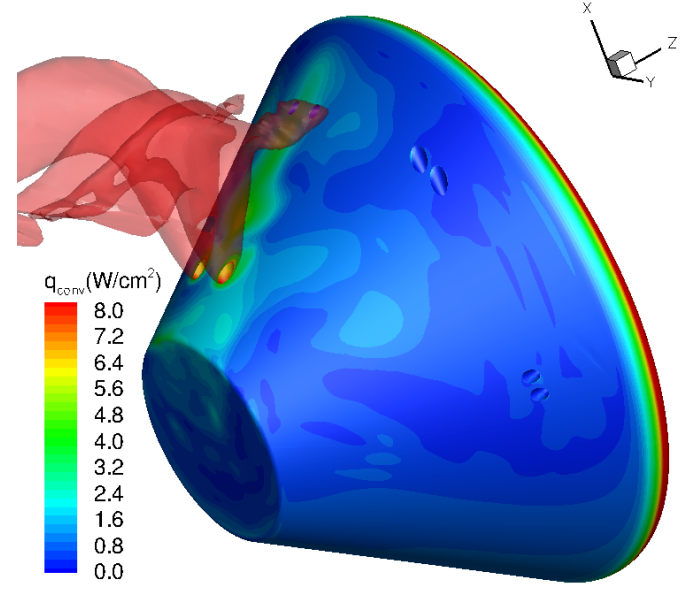

Figure 5. Flowfield, rear pitch jets, $4 \mathrm{~km} / \mathrm{sec}$

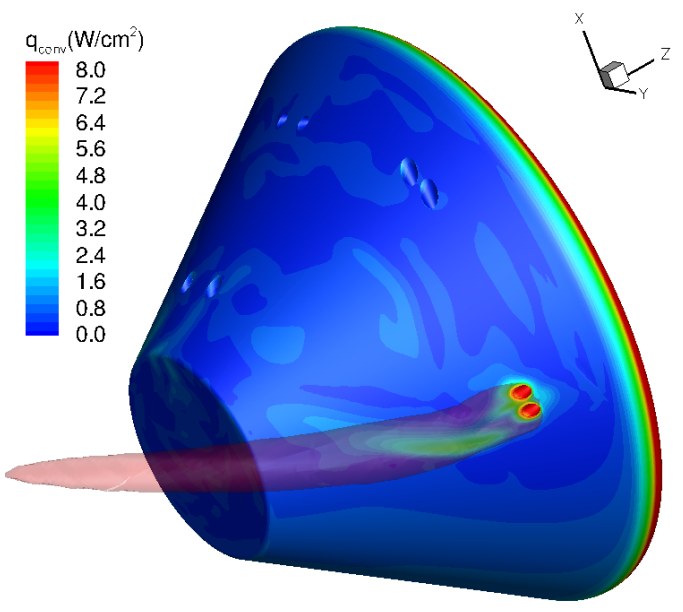

Figure 7. Flowfield, rear yaw jets, $4 \mathrm{~km} / \mathrm{sec}$

\section{RCS Heritage}

\section{A. Apollo Program}

Apollo program carried out ground testing of aeroheating augmentation due to RCS jets using the then-new phase change coating technique. Results of that work are summarized by Jones and Hunt $\left({ }^{10}\right)$. Authors found that interference heating on the Apollo shape was significant for yaw and roll jets. Augmentation factor of 4 due to yaw jet, factor of 11 due to forward-firing roll jets and a factor of 3 due to aft-firing 
roll jets. No appreciable augmentation was found due to pitch jets, which are located on the lee-side of the aftshell, and interact with recirculating flow. Interference heating in the case of the yaw and roll jets covered significant acreage of the backshell. In particular, forward-firing roll jets produced the most energetic interaction with the shear layer, coming off of the capsule's shoulder, and this yielded the greatest heating augmentation over the largest area.

Apollo entry capsules were instrumented to measure surface heating. Heating rate spikes on the lee-side of the spacecraft during entry were found to correspond to RCS jet firings and amounted to about a factor of 5 times the nominal measurement $\left({ }^{11}\right)$.

\section{B. Viking Program}

Viking program has made an attempt to measure experimentally the magnitude of jet-aerodynamic interference. A test was conducted in Mach 20 Helium wind tunnel, where thruster plumes were simulated as solid bodies. This test did not net any significant insight into the jet-wake interference because of the insufficient accuracy of the low AOA data $\left({ }^{13}\right)$. It was suggested, that the test be repeated with a balance, designed to measure smaller moments, but this was never carried out.

No attempts were made by Viking Project to measure aeroheating augmentation due to jets because aftbody heating was not expected to be significant $\left({ }^{14}\right)$. Viking was entered into Mars atmosphere from circular orbit at a relative velocity of about $4.6 \mathrm{~km} / \mathrm{sec}$. Low speed entry of a capsule with a relatively low ballistic coefficient $\left(\mathrm{m} / C_{D} A=63.7\right)$ resulted in very low heat fluxes on the aft-cover. Because these heatfluxes were low, on the order of $1 \mathrm{Watt} / \mathrm{cm}^{2}$, it was possible to make the aft-cover of aluminum, and not cover it with thermal protection material. Use of the small 8lbf thrusters for rate damping and for lift vector alignment would not produce the heat fluxes and heat loads much beyond the baseline. Therefore, it was not essential for Viking to test RCS aeroheating augmentation.

\section{Space Shuttle Orbiter}

Space Shuttle Orbiter is a lifting body winged vehicle and does not share aerodynamic characteristics with blunt entry capsules. Its experience is, however, valuable because of the insight gained in the course of ground tests and flight operations. The Program carried out multiple wind tunnel experiments to characterize jetaerodynamic interaction and to determine control effectiveness during entry. Flight data is also available from which to infer control effectiveness. Scallion has performed an analysis of the Shuttle post-flight and wind tunnel data with an excellent overview of a number of findings. ${ }^{15}$ He stressed the importance of the thruster plume shape and of the momentum ratio in order to achieve a correct magnitude of aerodynamic interaction based on observed performance. Because of the large amount of available wind tunnel and flight data it would be beneficial to validate numerical tools against these data sources.

\section{Recent and Future Tests}

\section{A. Nominal Aftbody Heating}

Orion Project has conducted numerous tests of nominal aftbody aeroheating environment. Investigations of aftbody heating by Hollis ${ }^{5}$ and Berger ${ }^{16}$ showed good agreement between heat flux predictions and measurement for both laminar and turbulent windside aftbody flowfields. In the case of transitional regime the laminar and turbulent predictions bounded data. Hollis dataset includes the leeside aftbody heating in the region of recirculating air. Variability and unsteadiness are highest in that region and all comparisons show that it is not possible to determine if the character of heating is laminar or turbulent there.

\section{B. Aftbody heating in presence of RCS jets}

Because of the long break in the use of actively controlled entry capsules Orion is one of the first recent projects to revisit aftbody aeroheating in presence of control system jets. Two series of exploratory tests have been conducted by Buck ${ }^{18}$ in Langley 31 inch Mach 10 air tunnel. Tests were carried out with a 5 inch diameter scale model of Orion capsule. There are differences between the jet location, orientation and

flow parameters between the first and second test series. Model aftbody was constructed of plastic and a steel forebody was used. Temperature sensitive paint (TSP) was selected as a global measurement method 
of choice. All current tests incorporate to some degree the scaling methodology outlined by Pindzola. ${ }^{19}$ Laminar CFD predictions have been made for the second test series. Analysis of data is in progress.

\section{Present Aerothermal Model of RCS effects}

Present model of aerothermal RCS interference effects is developed by Bomba. ${ }^{17}$ The model consists of a set of bump factors, that are applied to aftshell panels when specific thrusters are active. Bump factors are determined on the basis of recent and prior test data, Apollo flight data and CFD calculations. Figure 8 shows the layout of panels.

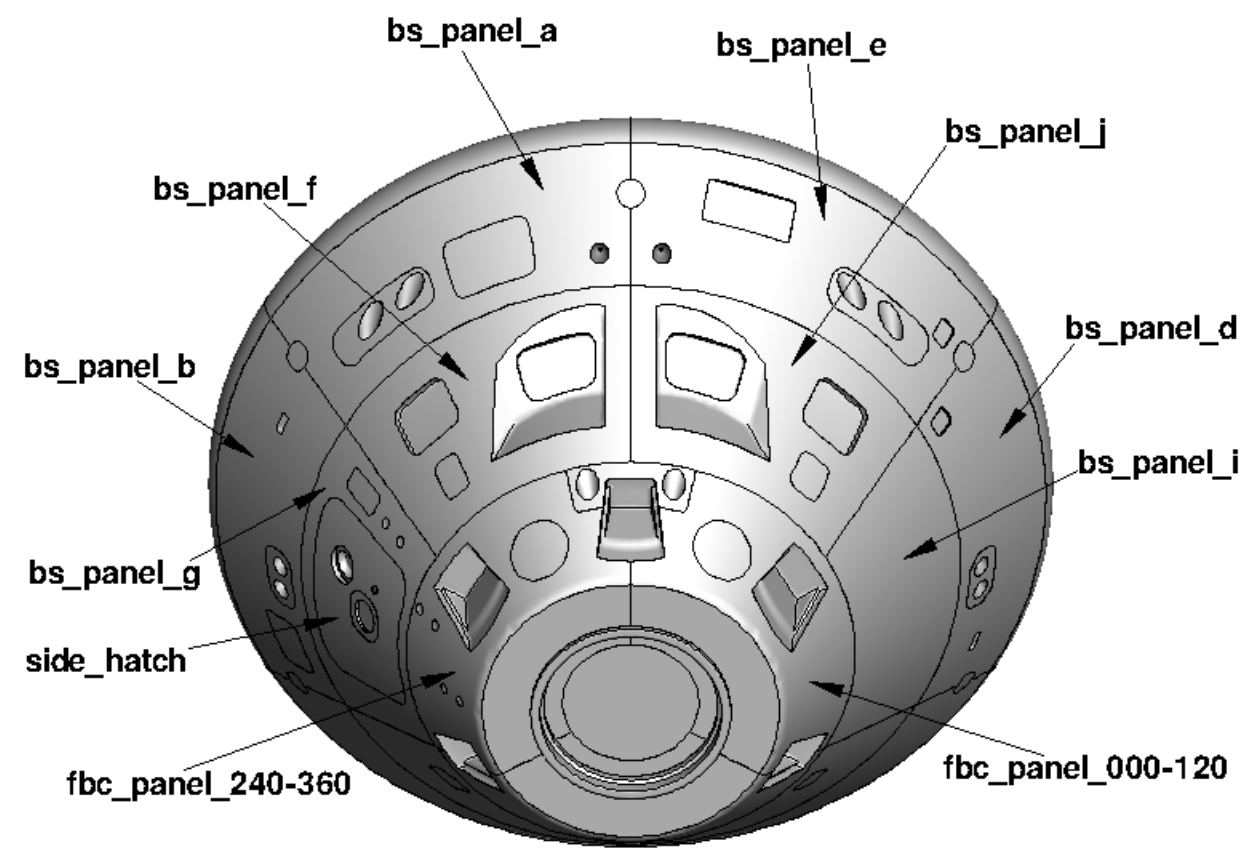

Figure 8. Panel layout.

\begin{tabular}{|r|r|r|r|r|}
\hline \multicolumn{5}{|c|}{ Panel augmentation factors } \\
\hline \hline Panel & Left Yaw & Left Roll & Front Pitch & Rear Pitch \\
\hline bs_panel_a & 1 & $3(5)^{*}$ & 1.5 & 1 \\
\hline bs_panel_b & 5 & 1 & 1.5 & 1 \\
\hline bs_panel_f & 1 & 1 & 1.5 & 1 \\
\hline bs_panel_g & 5 & 1 & 1.5 & 1 \\
\hline side_hatch & 5 & 1 & 1.5 & 1 \\
\hline bs_panel_e & 1 & 1 & 1.5 & 1 \\
\hline bs_panel_i & 1 & 1 & 1.5 & 1 \\
\hline bs_panel_j & 1 & 1 & 1.5 & 1 \\
\hline bs_panel_d & 1 & 1 & 1.5 & 1 \\
\hline fbs_panel_240-360 & 4 & 1 & 1.5 & 3 \\
\hline
\end{tabular}

The table shows the numbers for the bump factors for the left side assuming symmetry when right side thrusters are used. Asterisk is indicating that a higher factor of (5) is applied to the rear half of the panel bs_panel_a under roll condition. Application of the bump factor is multiplicative with other bump factors, such as cavity effects. 


\section{Numerical Analysis}

\section{A. CFD Model}

In order to quantify effects of RCS jets on the aeroheating environment of Orion entry capsule a numerical model was developed. In the present model air is a 5 -specie non-equilibrium mixture (below $9 \mathrm{~km} / \mathrm{sec}$ ) or an 11-specie non-equilibrium mixture (above $9 \mathrm{~km} / \mathrm{sec}$ ). Flow is laminar and CFD domain assumes no pitch-plane symmetry, to allow for three-dimensionality of the wake in presence of asymmetrically activated jets. Additional calculations were performed on the geometry, consistent with a 5 -inch wind tunnel model as tested in Langley Mach 10 tunnel. These calculations used air as perfect gas and were used to provide initial code comparison between LAURA and DPLR. Comparison of the code predictions with the results of the wind tunnel test is ongoing.

\section{B. Mach 10 Perfect Gas Calculations, Code Comparisons}

Calculations have been performed for a range of wind tunnel conditions and RCS nozzle fflow conditions. Figure 10 shows a comparison of LAURA and DPLR predictions at the conditions of LaRC Mach 10 test. Predictions fall within .3\% of the reference heat flux. Figures 11 and 12 show a comparison of laminar LAURA and DPLR predictions for the same conditions with a single active yaw jet. Generally the predictions compare favorably, with the difference in peak about $3 \%$ of the reference heat flux. Figures 13 and 14 show the LAURA/DPLR comparison for a simulation with a pair of yaw jets. This more complex flow results in up to a factor of two difference in predictions in the narrow region upstream of the nozzle exits. The reason for this disagreement is being analyzed. Heating predictions have shown to be sensitive to surface and volume grid refinement. Solutions so far don't show monotonic convergence with grid refinement. The range of grid sizes in this study was between $6.5 \mathrm{M}$ and $52 \mathrm{M}$ points. While it may be possible to obtain a grid level that will afford grid independence, it may also be possible that the wake will not reach a steady behavior and will continue to change with every grid refinement for any reasonable grid size. It may, therefore, be reasonable to compute on lower grid levels and mind grid sensitivity as a term in the uncertainty of the method. Additional source of difference between LAURA and DPLR solutions may be the difference in the solution advancement. LAURA uses a local time step evaluation, while DPLR uses a global time step. For a steady flow both should generally achieve the same solution, however the difference in advance rate may play a role in separated unsteady wakes. While certainly a valid concern, this hasn't been a focus of the present study as the main objective here is to quantify jet-wake interaction phenomena, which are typically steady.

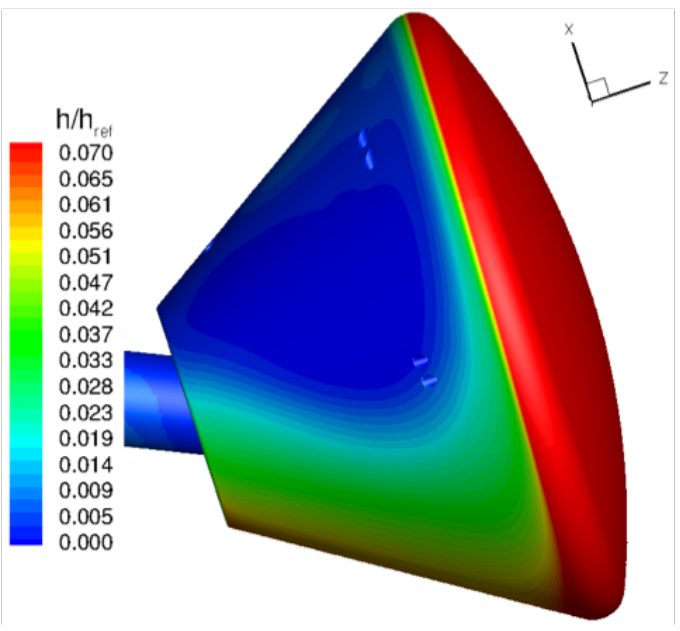

Figure 9. Representative laminar aftbody heating distribution, Run 18 condition

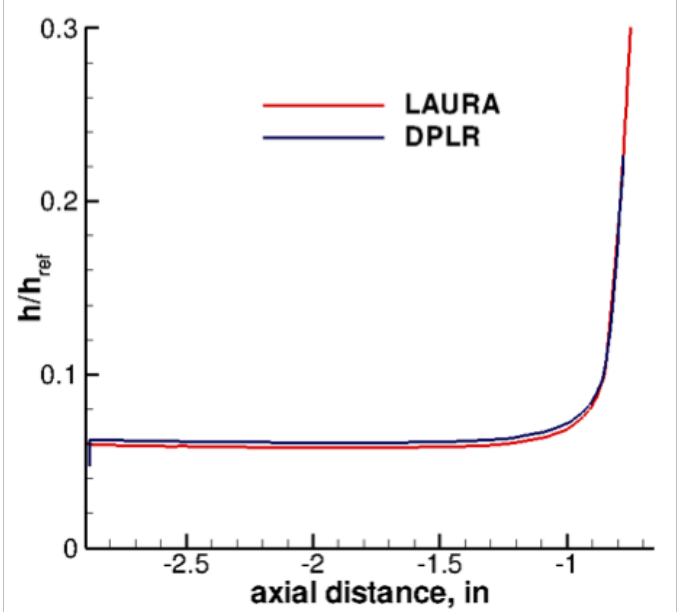

Figure 10. Windside aftbody comparison, run 18 


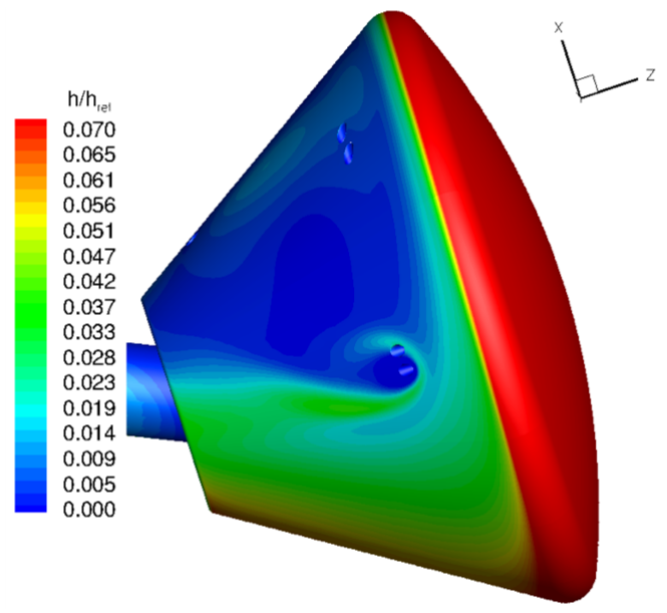

Figure 11. Single yaw jet, LAURA

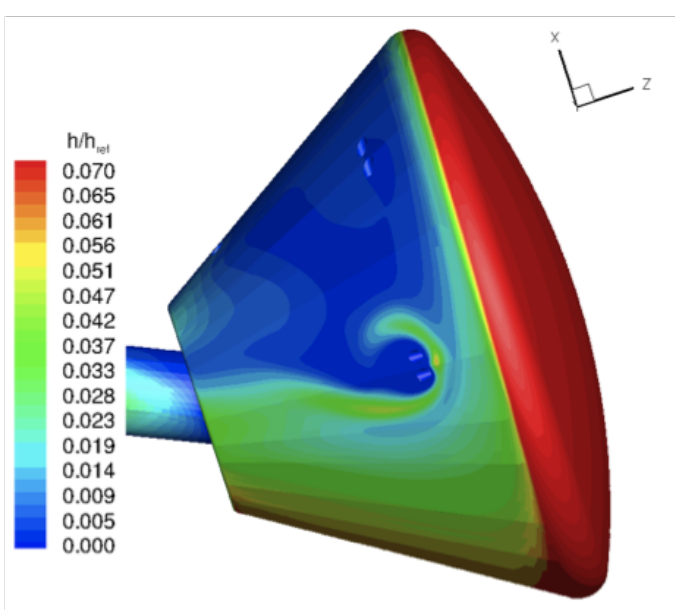

Figure 13. Dual yaw jet, LAURA

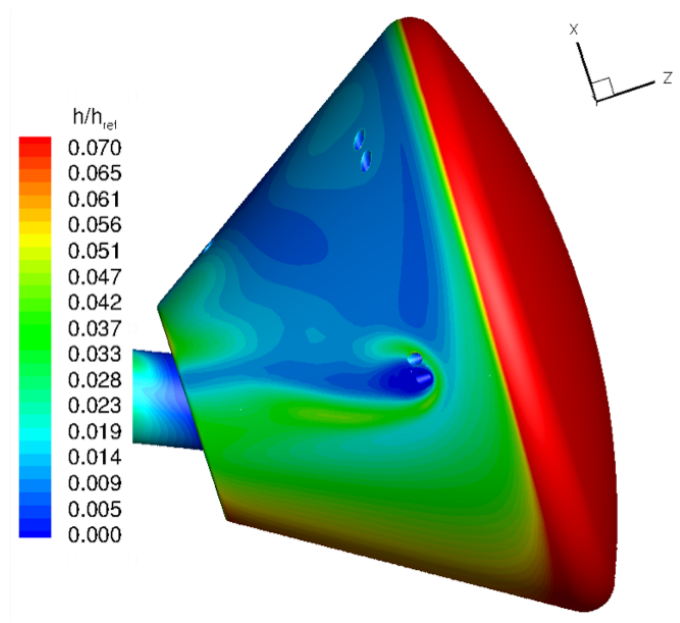

Figure 12. Single yaw jet, DPLR

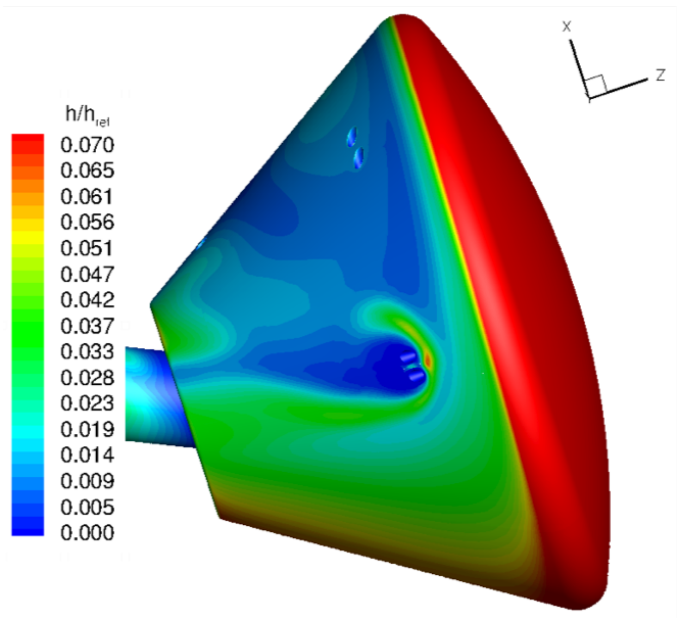

Figure 14. Dual yaw jet, DPLR

\section{Flight trajectory Conditions}

Current analysis of flight environments is being carried out for a series of entry trajectories. Skip-out and non-skip-out trajectories are used to define trajectory space and provide free-stream conditions of interest to the CFD analysis as shown in the figure 15. The intent is to isolate effects of dynamic pressure and Mach number across various segments of the hypersonic flight regime so an engineering model of the phenomena can be constructed.

\section{Analysis at hypersonic conditions}

Several conditions have been evaluated. Figures 16, 17 and 18 show convective heatrates predicted by LAURA on the aftshell in presence of roll RCS jets at the conditions of $5 \mathrm{~km} / \mathrm{sec}, 4 \mathrm{~km} / \mathrm{sec}$ and $2 \mathrm{~km} / \mathrm{sec}$ in flight. No margins are applied to the shown results. Calculations are laminar and show an elevated heatrate due to RCS jet displacing the free mixing layer and recovering some of the energy of the external flow. Notably, the heatrate is expected to vary with some free-stream parameters, and additional calculations are in progress with the intent to help make assertions regarding any functional dependencies. In the mean time the solutions that are available suggest that dynamic pressure correlates the RCS aeroheating augmentation, but the information is not sufficient to determine the functionality. 


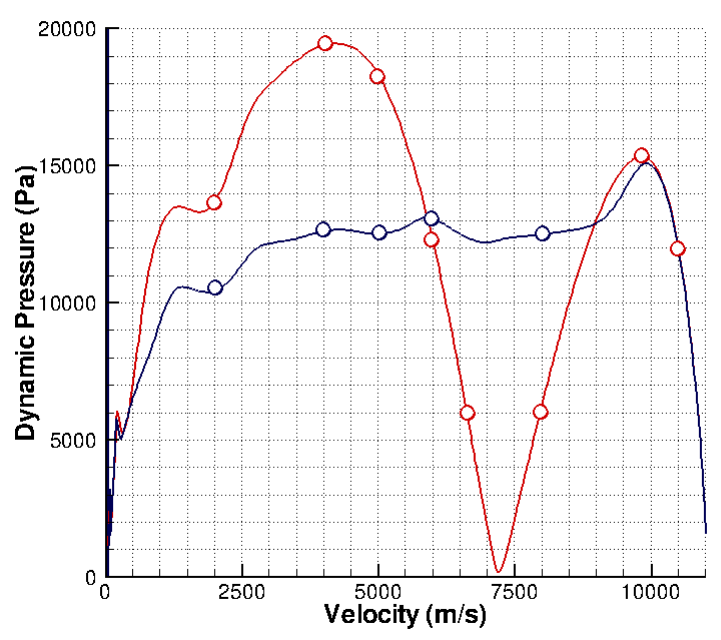

Figure 15. Entry trajectory profiles

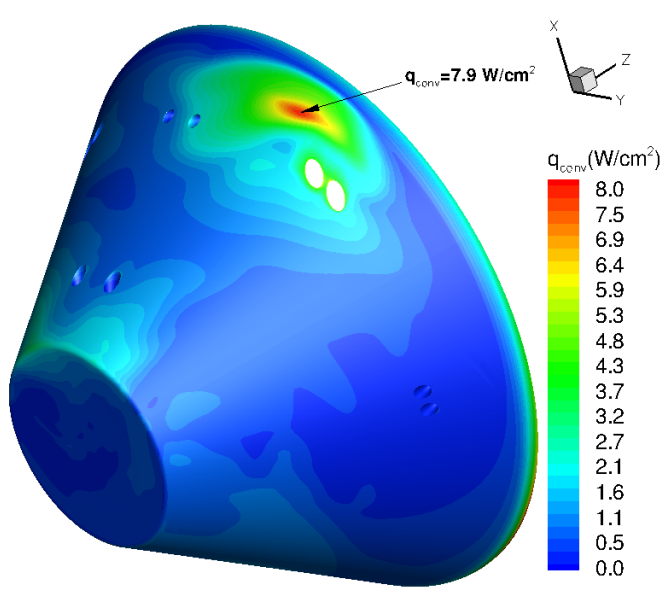

Figure 17. $4 \mathrm{~km} / \mathrm{s}$ heatrate (roll RCS)

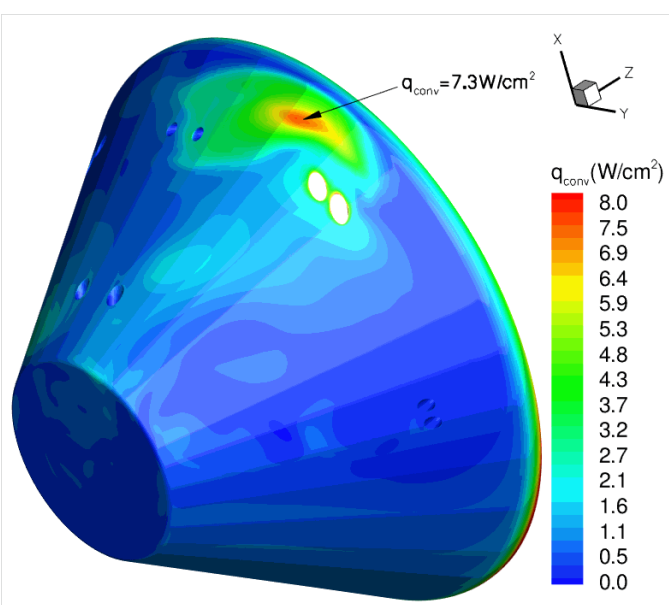

Figure 16. $5 \mathrm{~km} / \mathrm{s}$ heatrate (roll RCS)

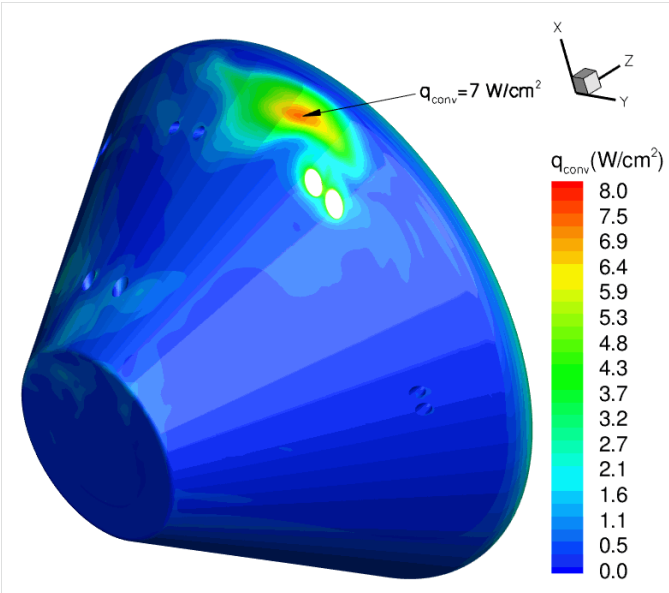

Figure 18. $2 \mathrm{~km} / \mathrm{s}$ heatrate (roll RCS)

\section{E. Grid Refinement}

Calculations were performed at different grid levels to assess this sensitivity. The condition of $4 \mathrm{~km} / \mathrm{sec}$ with roll thrusters was chosen for this analysis. LAURA solutions evaluated on $15 \mathrm{M}$ and $56 \mathrm{M}$ point grids show a difference of about $12 \%$ in predicted augmented heating as shown in the figures 19 and 20.

\section{F. Model Uncertainty}

Presently an uncertainty of $50 \%$ is applied to the heatflux after the bump factor. The intent is to update the present uncertainty model based on tests, code-to-code comparisons and engineering analyses.

\section{G. Discussion of the Limitations of the Current CFD Model}

So far the model has several shortcomings, that are discussed here. As mentioned in the section on the Mixing Layer the standard practice grid alignment in LAURA and DPLR results in a sub-optimal grid in the wake region. Specifically, grid planes tend to intersect the free layer at an odd angle and the grid density is insufficient to support transport phenomena across the layer. This calls into question air pressure 


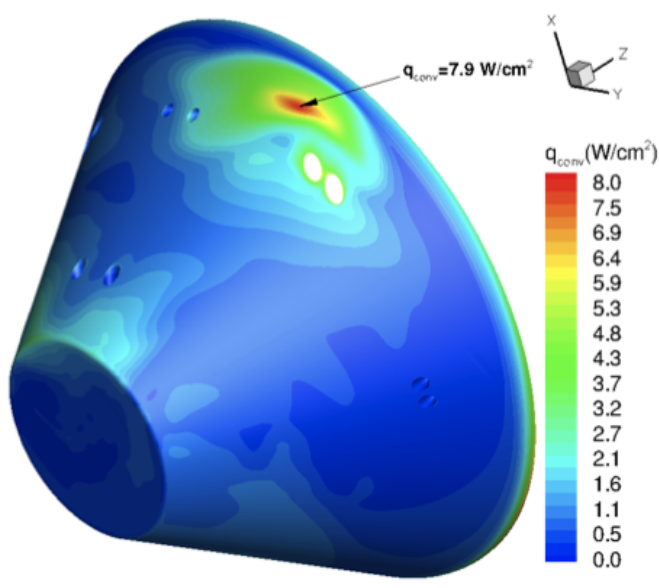

Figure 19. $4 \mathrm{~km} / \mathrm{s}$ heatrate (roll RCS), 15M point grid

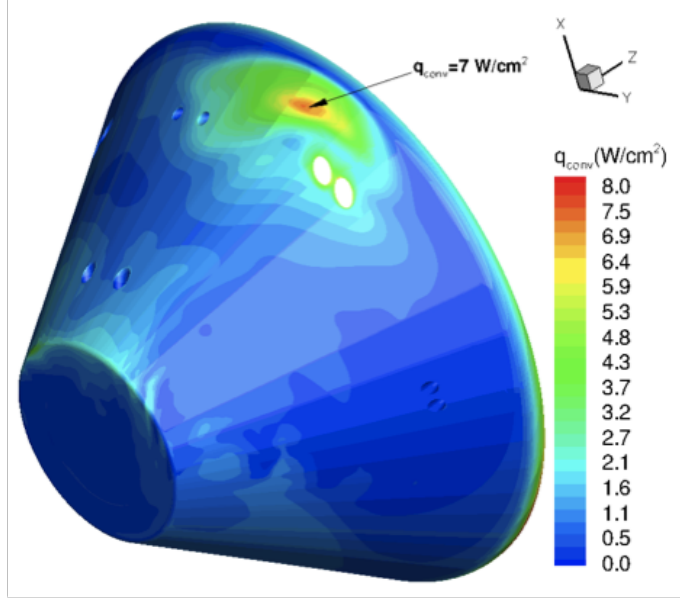

Figure 20. $4 \mathrm{~km} / \mathrm{s}$ heatrate (roll RCS), 56M point grid

and enthalpy computed in the recirculating zone. As a result of this, the wake angle can be in incorrect, producing errors in the predicted parameters of the external flow. To determine sensitivity of all mentioned parameters engineering approach shell will be used. As far as the calculation of RCS-induced heating is concerned, the main areas of RCS-induced heating are caused by steady impingement and should not be significantly influenced by errors in the recirculating wake.

While the present model treats air as a non-equilibrium mixture, the RCS effluent is implemented as a non-reacting surrogate gas with properties of ammonia (NH3). Molecular weight of ammonia is close to the molecular weight of RCS effluent (mix of ammonia, hydrogen and nitrogen) but the effects of chemical reactions involving all species is not yet assessed. To determine the sensitivity to the missing physics both LAURA_5 and DPLR will be used.

Commonly recognized issue with the computation of complex hypersonic flowfields with separation is the absence of time accuracy. In the case of unsteady and vortical flows this results in an evolving non-convergent solution where a quazi-time (measure of evolution rate) at any given location has no strict relation to that at any other location. In other words, no claims are made to time consistency of the recirculating system. While this remains an open subject, as far as the calculation of RCS-induced heating is concerned, the main areas of RCS-induced heating are caused by steady impingement and should not be influenced by the details of the time domain of the recirculating wake.

\section{H. Additional Model Details, Future Work}

Several future additions to the model are planned. As discussed above, the present implementation of RCS effluent as inert surrogate gas produces only convective component of heating. It is necessary to add other species in the RCS mixture and allow them to react with the surrounding gas. This will be carried out with both new version of LAURA and DPLR. Chemical interaction of thermal protection system (TPS) tiles with RCS effluent needs to be understood. If any significant interactions exist at the local conditions, specific to the interference flowfield, these details will need to be included in the model. Lastly, sensitivity of the predicted RCS-induced heating to errors in the wake calculation needs to be assessed. The mechanism to accomplish this is still being developed. Uncertainty of the predictive method will depend on the future comparisons with experimental data. Most of the aftbody heating data that is available for code validation doesn't include effects of RCS. Langley Mach 10 data set ${ }^{18}$ is still being analysed. Several future tests are in design phases. Along with code comparisons and development of engineering models of the phenomena this data is important to the understanding of the aftbody TPS environment in presence of RCS thruster plumes. 


\section{Conclusions}

An overview of the investigation of effects of the Orion reaction control system thruster plumes on aerothermal environment is presented. Computer model has been developed and applied to the wind tunnel and flight environments. The computer model of the phenomena is under continued development, and additions are planned. Main concerns at the present time are the understanding of turbulent transition in the mixing layers in the flowfield, modeling of the mixing layers in CFD and RCS effluent chemistry. Validation of codes through wind tunnel tests is ongoing. Aeroheating augmentation was fond to be maximum in the presence of roll jet firings, followed in magnitude by yaw thrusters and aft pitch thrusters. Forward pitch thrusters are not expected to produce any significant aeroheating augmentation. Limited computations indicate a notional correlation of roll RCS heating with free-stream dynamic pressure. Extent of the present analysis does not yet allow to derive functional dependencies. It is expected that the augmentation due to other thrusters will follow the dynamic pressure trend that appears to hold for roll thrusters. The numerical technique has been discussed. Modeling details that need addressing in the future have been identified.

\section{Acknowledgments}

Authors would like to thank Victor Lessard of NASA Langley for his help with creation of CFD grids used in the present analysis. Special thanks also go to Chun Tang and Ryan McDaniel of NASA Ames for their help with DPLR analysis.

\section{References}

${ }^{1}$ Schoenenberger M. et. al. Aerodynamic Challenges for the Mars Science Laboratory Entry Descent and Landing, AIAA Paper 2009-3914, San Antonio, Texas, June 2009.

${ }^{2}$ Cheatwood, F. M. and Gnoffo, P. A., Users Manual for the Langley Aerothermodynamic Upwind Relaxation Algorithm (LAURA), NASA TM-4674, April 1996.

${ }^{3}$ Wright M. J., Candler G. V. and Bose, D., Data-Parallel Line Relaxation Method for the Navier-Stokes Equations, AIAA Journal, Vol.36, No.9, September 1998.

${ }^{4}$ Hollis B. R., et. al. Aeroheating Testing and Predictions for Project Orion CEV at Turbulent Conditions, AIAA Paper 2008-1226, Proceedings of AIAA Aerospace Science Meeting and Exhibit, Reno, Nevada, January 2008.

${ }^{5}$ Hollis B. R., et. al. Aeroheating Testing and Predictions for Project Orion CEV at Turbulent Conditions, AIAA Paper 2008-1226, Proceedings of AIAA Aerospace Science Meeting and Exhibit, Reno, Nevada, January 2008.

${ }^{6}$ Horvath, T. J. et al., Experimental Hypersonic Aerodynamic Characteristics of Mars Surveyor 2001 Precision Lander with Flap, JSR Vol. 43, No. 2, March-April 2006.

${ }^{7}$ Chapman D. R., Kuehn D. M. and Larson H. K., Prelimimnary Report on Study of Separated Flows in Supersonic and Subsonic Streams, NACA RM A55L14, June 1956.

${ }^{8}$ von Doenhoff A. E., A Preliminary Investigation of Boundary Layer Transition Along a Flat Plate with Adverse Pressure Gradient, NACA TN 639, 1938.

${ }^{9}$ Spaid F. W. and Cassel L. A., Aerodynamic Interference Induced by Reaction Controls, AGARD-AG-173, 1973.

${ }^{10}$ Jones, R. A. and Hunt J. L., Effects of Cavities, Protuberances, and Reaction-Control Jets on Heat Transfer to the Apollo Command Module, NASA TM X-1063, 1965.

${ }^{11}$ Lee D. B., Bertin J. J. and Goodrich W. D., Heat-Transfer Rate and Pressure Measurements Obtained During Apollo Orbital Entries, NASA TN D-6028, 1970.

${ }^{12}$ Adkins E.J. et. al., Entry Vehicle Control, NASA SP-8028, 1969.

${ }^{13}$ Blake W. W. and Polutchko R. J., Hypersonic Experimental Aerodynamic Characteristics of Viking Lander Capsule, Martin Marietta, TR-3709012, 1970.

${ }^{14}$ Siemers P. M., Personal communication, NASA Langley, 2008.

${ }^{15}$ Scallion W. I., Space Shuttle Reaction Control System - Flow Filed Interaction During Entry, Proceedings of the NASA Aerodynamics Symposium, Williamsburg, VA, April 27-30 1993.

${ }^{16}$ Berger K. T., Aerothermodynamic Testing of the Crew Exploration Vehicle in the LaRC 20-Inch Mach 6 and 31-Inch Mach 10 Tunnels, AIAA Paper 2008-1225, Proceedings of AIAA Aerospace Science Meeting and Exhibit, Reno, Nevada, January 2008.

${ }^{17}$ Bomba J.V., Personal communication, NASA JSC, 2008.

${ }^{18}$ Buck G. M. et. al. Experimental Measurement of RCS Jet Interaction Effects on a Capsule Entry Vehicle, AIAA Paper 2008-1229, Reno, Nevada, January 2008.

${ }^{19}$ Pindzola M., Jet Simulation in Ground Test Facilities, AGARDograph, November 1963. 